\title{
Estratégias lúdicas na reabilitação motora de crianças com paralisia cerebral: revisão integrativa
}

Livia Willemann Peres ${ }^{1}$, Ana Carolina Andrade Biaggi Leite ${ }^{2}$, Willyane de Andrade Alvarenga ${ }^{3}$, Mona Moamad Al Ghazaoui ${ }^{4}$, Tamara Mohamad Rahall ${ }^{5}$, Lucila Castanheira Nascimento ${ }^{6}$

\section{RESUMO}

Objetivou-se identificar e analisar as estratégias lúdicas utilizadas na reabilitação de desordens motoras em crianças com paralisia cerebral. Trata-se de uma revisão integrativa da literatura, conduzida por dois revisores independentes, nas bases de dados LILACS, EMBASE, Web of Science, CINAHL e PubMed. As buscas abrangeram o período de 2006 a 2017 e os idiomas português, inglês e espanhol. A estratégia de busca contemplou várias palavras-chaves, utilizando-se a abordagem PICO. Foram incluídos 20 artigos e os resultados mostraram-se satisfatórios na utilização de estratégias lúdicas, com foco na motricidade fina, motricidade grossa, equilíbrio e marcha das crianças com paralisia cerebral. Os videogames e os jogos de computador foram as estratégias mais utilizadas. Conclui-se que a incorporação do lúdico no tratamento de crianças com paralisia cerebral, desde que utilizado de maneira adequada, é importante para subsidiar a melhora das habilidades motoras e favorecer a relação terapeuta/paciente, tornando o tratamento mais dinâmico e eficaz.

Descritores: Revisão; Paralisia Cerebral; Criança; Reabilitação; Ludoterapia; Enfermagem Pediátrica.

\footnotetext{
${ }^{1}$ Fisioterapeuta, Mestre em Ciências do Movimento Humano. Discente do Programa de Pós-Graduação Enfermagem em Saúde Pública, nível Doutorado, da Escola de Enfermagem de Ribeirão Preto da Universidade de São Paulo. Mestre em Ciências do Movimento Humano. Professora do Centro de Ensino Superior de Foz do Iguaçu. Foz do Iguaçu, PR, Brasil. E-mail: liviawillemann@gmail.com.

${ }^{2}$ Enfermeira. Discente do Programa Interunidades de Doutoramento em Enfermagem da Escola de Enfermagem/Escola de Enfermagem de Ribeirão Preto da Universidade de São Paulo. Ribeirão Preto, SP, Brasil. E-mail: ana.andrade.leite@usp.br.

${ }^{3}$ Enfermeira, Doutora em Enfermagem em Saúde Pública. Ribeirão Preto, SP, Brasil. E-mail: willyalvarenga@hotmail.com.

${ }^{4}$ Acadêmica do curso de graduação em Fisioterapia do Centro Universitário União Dinâmica das Cataratas - Unidade Vila A. Foz do Iguaçu, PR, Brasil. E-mail: monaghazaoui28@gmail.com.

${ }^{5}$ Acadêmica do curso de graduação em Fisioterapia do Centro Universitário União Dinâmica das Cataratas - Unidade Vila A. Foz do Iguaçu, PR, Brasil. E-mail: tamararahall28@gmail.com.

${ }^{6}$ Enfermeira, Doutora em Enfermagem. Professora Associada da Escola de Enfermagem de Ribeirão Preto da Universidade de São Paulo. Ribeirão Preto, SP, Brasil. E-mail: lucila@eerp.usp.br.
}

Artigo recebido: 31/12/2017.

Artigo aprovado: 29/03/2018.

Artigo publicado: $21 / 11 / 2018$.

\section{Como citar esse artigo:}

Peres LW, Leite ACAB, Alvarenga WA, Al Ghazaoui MM, Rahall TM, Nascimento LC. Estratégias lúdicas na reabilitação motora de crianças com paralisia cerebral: revisão integrativa. Rev. Eletr. Enf. [Internet]. 2018 [acesso em: ];20:v20a25. Disponível em: https://doi.org/10.5216/ree.v20.50936. 


\section{INTRODUÇÃO}

A paralisia cerebral (PC), também conhecida como Encefalopatia Crônica Não Progressiva da Infância (ECNPI), é a incapacidade física mais comum da infância. Refere-se às desordens do desenvolvimento motor decorrentes de lesão cerebral primária, de caráter permanente e mutável, que ocasionam alterações musculoesqueléticas secundárias e limitações nas atividades cotidianas da criança ${ }^{(1)}$. Pacientes com PC demonstram problemas de anormalidades do tônus muscular, comprometimento do equilíbrio e coordenação, diminuição da força e perda de controle na seletividade do movimento(2).

Devido às alterações musculoesqueléticas, promover o desempenho de atividades funcionais ${ }^{(3)}$ e minimizar o desenvolvimento de problemas secundários como as deformidades, por exemplo(4), são objetivos a serem alcançados pelas terapêuticas empregadas. Dentre elas, destaca-se a reabilitação, que deve considerar o indivíduo com base nos aspectos físicos, mentais, emocionais, comunicativos e relacionais, além do seu contexto familiar, social e ambiental(5).

Há uma diversidade de metodologias de intervenção adotadas na reabilitação de crianças com PC. Algumas revisões da literatura têm avaliado o efeito de intervenções isoladas comumente usadas para os distúrbios motores na PC, como a realidade virtual, jogos interativos e videogames ${ }^{(6-8)}$. No entanto, não há uma revisão que integre essas diferentes abordagens e especifique as terapias de caráter lúdico com resultados capazes de auxiliar os profissionais de saúde na seleção da melhor estratégia de tratamento para a reabilitação dessas crianças.

Brincar é uma atividade natural na infância e potencialmente geradora de muitas oportunidades para que a criança com PC melhore sua capacidade motora ${ }^{(9-10)}$. Considerar estratégias lúdicas na reabilitação de desordens motoras pode ter efeito potencializador no desenvolvimento da criança com PC, tendo em vista os componentes sensoriais, motores, cognitivos, afetivos e sociais do brincar ${ }^{(11)}$.

Ao se utilizar o lúdico como estratégia é possível expandir o nível de atividade e a participação da criança, além de promover uma abordagem centrada no paciente. Portanto, com a questão "Quais são as estratégias lúdicas utilizadas na reabilitação para melhorar a capacidade motora da criança com PC?", esta revisão integrativa teve a proposta de identificar e analisar as estratégias lúdicas utilizadas na reabilitação de desordens motoras em crianças com PC.

\section{MÉTODO}

Realizou-se uma revisão integrativa da literatura, que incluiu as fases de identificação do problema, busca na literatura, análise e avaliação dos dados e síntese para reportar os resultados ${ }^{(12)}$. Foi utilizada a abordagem PICO para desenvolver a questão da revisão, o escopo e os critérios de inclusão (População, Intervenção, Controle e Resultado) ${ }^{(13)}$, a qual está ilustrada no Quadro 1.

Quadro 1: Descritores de assunto empregados na busca dos artigos. Ribeirão Preto/SP, 2017.

\begin{tabular}{|c|c|}
\hline \multicolumn{2}{|c|}{ Estratégia PICO } \\
\hline $\mathbf{P}$ & Crianças menores de 12 anos com diagnóstico de PC \\
\hline I & Estratégias lúdicas \\
\hline C & Não se aplica \\
\hline $\mathbf{O}$ & Reabilitação (motora) \\
\hline
\end{tabular}


A revisão incluiu estudos originais, publicados na íntegra em revistas científicas e em anais de eventos, com crianças menores de 12 anos de idade, diagnosticadas com PC, desde que avaliassem uma intervenção de abordagem lúdica para a criança. Não foram referidos grupos de comparação e os resultados dos estudos deveriam abordar a função motora da criança (por exemplo: motricidade fina, motricidade grossa, equilíbrio e marcha). Foram considerados todos os delineamentos de estudos, ou seja, com abordagens quantitativas e qualitativas, a fim de abranger a diversidade de estratégias lúdicas já utilizadas com crianças com PC. Excluíramse os artigos com adolescentes (idade acima de 12 anos), que não apresentavam separadamente os resultados relativos à criança; aqueles que incluíram diferentes diagnósticos e que não apresentavam separadamente os resultados relativos à PC; e aqueles que utilizaram qualquer intervenção alternativa no grupo de comparação. Também foi excluída a literatura cinzenta, como livros, capítulos de livros, teses e dissertações e resumos publicados em anais de eventos.

A busca foi conduzida por dois revisores independentes nas bases de dados LILACS, EMBASE, Web of Science, CINAHL e PubMed. A estratégia contemplou uma ampla série de palavras-chaves relacionadas com criança, PC, reabilitação, jogos, brinquedos e ludoterapia. Os termos de busca e a estratégia empregada na PubMed são apresentados no Quadro 2 e foram similares nas outras bases, adequando-se às especificidades de cada uma delas. Alguns limites foram aplicados, como os relacionados ao período de 2006 a 2017, aos idiomas português, inglês e espanhol e a pesquisas com humanos. Também foram verificadas as listas de referências dos artigos incluídos.

Quadro 2: Termos de busca utilizados na PubMed.

\begin{tabular}{|c|c|}
\hline Grupo & Descritores e palavras-chaves \\
\hline 1 & $\begin{array}{l}\text { "Cerebral Palsy"[Mesh] OR CP (Cerebral Palsy) OR (Cerebral Palsy, Dystonic-Rigid) OR (Cerebral Palsies, Dystonic-Rigid) } \\
\text { OR (Cerebral Palsy, Dystonic Rigid) OR (Dystonic-Rigid Cerebral Palsies) OR (Dystonic-Rigid Cerebral Palsy) OR (Cerebral } \\
\text { Palsy, Mixed) OR (Mixed Cerebral Palsies) OR (Mixed Cerebral Palsy) OR (Cerebral Palsy, Monoplegic, Infantile) OR } \\
\text { (Monoplegic Infantile Cerebral Palsy) OR (Infantile Cerebral Palsy, Monoplegic) OR (Cerebral Palsy, Quadriplegic, } \\
\text { Infantile) OR (Quadriplegic Infantile Cerebral Palsy) OR (Infantile Cerebral Palsy, Quadriplegic) OR (Cerebral Palsy, } \\
\text { Rolandic Type) OR (Rolandic Type Cerebral Palsy) OR (Cerebral Palsy, Congenital) OR (Congenital Cerebral Palsy) OR } \\
\text { (Little Disease) OR (Little's Disease) OR (Spastic Diplegia) OR (Diplegias, Spastic) OR (Spastic Diplegias) OR (Diplegia, } \\
\text { Spastic) OR (Monoplegic Cerebral Palsy) OR (Cerebral Palsies, Monoplegic) OR (Cerebral Palsy, Monoplegic) OR } \\
\text { (Monoplegic Cerebral Palsies) OR (Cerebral Palsy, Athetoid) OR (Athetoid Cerebral Palsy) OR (Cerebral Palsies, } \\
\text { Athetoid) OR (Cerebral Palsy, Dyskinetic) OR (Cerebral Palsies, Dyskinetic) OR (Dyskinetic Cerebral Palsy) OR (Cerebral } \\
\text { Palsy, Atonic) OR (Atonic Cerebral Palsy) OR (Cerebral Palsy, Hypotonic) OR (Hypotonic Cerebral Palsies) OR (Hypotonic } \\
\text { Cerebral Palsy) OR (Cerebral Palsy, Diplegic, Infantile) OR (Diplegic Infantile Cerebral Palsy) OR (Infantile Cerebral } \\
\text { Palsy, Diplegic) OR (Cerebral Palsy, Spastic) OR (Spastic Cerebral Palsies) OR (Spastic Cerebral Palsy) }\end{array}$ \\
\hline 2 & "Child"[Mesh] OR (c \\
\hline 3 & 1 AND 2 \\
\hline 4 & $\begin{array}{l}\text { "Video Games"[Mesh] OR (Game, Video) OR (Games, Video) OR (Video Game) OR (Computer Games) OR (Computer } \\
\text { Game) OR (Game, Computer) OR (Games, Computer) OR "Play and Playthings"[Mesh] OR (Playthings and Play) OR } \\
\text { (Toys) OR (Toy) OR (Puppets) OR (Puppet) OR (Play) OR (Plays) OR (Playthings) OR (Plaything) OR "Play Therapy"[Mesh] } \\
\text { OR (Play Therapies) OR (Therapies, Play) OR (Therapy, Play) OR (Sandplay Therapy) OR (Sandplay Therapies) OR } \\
\text { (Therapies, Sandplay) OR (Therapy, Sandplay) OR (Sandplay) OR (Sandplays) }\end{array}$ \\
\hline 5 & "Rehabilitation"[Mesh] OR (habilitation) OR (motor rehabilitation) \\
\hline 6 & 3 AND 4 AND 5 \\
\hline
\end{tabular}

As referências foram exportadas para o EndNote ${ }^{\oplus}$, para fins de organização e verificação das duplicidades. Houve a leitura dos títulos e resumos dos artigos por dois pesquisadores independentes, baseando-se nos critérios 
de elegibilidade da revisão. Realizou-se o teste Kappa para verificação da concordância interobservadores, o que demostrou concordância quase perfeita, com valor de $0,88^{(14)}$. Posteriormente, dois pesquisadores fizeram, de modo independente, a leitura na íntegra dos artigos considerados relevantes para a inclusão nesta revisão. Divergências entre ambos foi resolvida por consenso e mediante auxílio de um terceiro revisor. Utilizou-se o fluxograma do PRISMA para ilustrar os resultados da busca, triagem e processo de seleção para identificação dos estudos incluídos na revisão(15).

A extração dos dados foi conduzida por dois revisores independentemente e norteada por um formulário de coleta dos dados elaborado pelos pesquisadores. Desacordos entre os revisores em relação aos dados extraídos eram discutidos, tendo como referência a publicação original. Extraíram-se as seguintes informações: identificação, método do estudo, características das crianças do estudo, tipo de intervenção e formato, cenário, resultados relacionados ao desenvolvimento motor, medidas utilizadas, limitação e conclusões apresentadas.

Não foi possível realizar uma meta-análise, devido à heterogeneidade dos estudos, e fez-se uma síntese narrativa. Os resultados da revisão foram estruturados em relação aos seguintes aspectos: descrição dos estudos, tipos de intervenção, medidas utilizadas e impactos das intervenções, explorando-se também a relação entre os estudos e seus resultados.

\section{RESULTADOS}

Ao todo, foram identificados 425 estudos, 423 deles por meio das buscas nas bases de dados e dois pela verificação das referências dos artigos incluídos. Destes, 50 foram excluídos por estarem duplicados, prosseguindo a leitura de títulos e resumos de 375 artigos. Baseados nos critérios de elegibilidade, 294 artigos foram excluídos, o que resultou na análise amostral de 81 estudos para leitura na íntegra. Após essa leitura, 20 artigos foram incluídos nesta revisão. $O$ processo de busca na literatura, baseado nas recomendações do PRISMA ${ }^{(15)}$, está representado na Figura 1.

O Quadro 3 ilustra as características dos estudos incluídos ${ }^{(16-35)}$. Eles foram realizados entre 2007 e 2017; a maioria das intervenções foi desenvolvida na Europa $(n=7)^{(18-19,23,25-27,30)}$, em países como Holanda $(n=4)^{(18-19,23,26)}$, Espanha $(n=1)^{(25)}$, Dinamarca $(n=1)^{(27)}$ e Reino Unido $(n=1)^{(30)}$. A América do Norte ${ }^{(17,20-21,24,29,33)}$ e a Ásia $a^{(16,22,28,31-}$ ${ }^{32,34-35)}$ apresentaram seis estudos cada, destacando-se os Estados Unidos ${ }^{(17,20,24,33)}$ no desenvolvimento de quatro intervenções.

Dentre as metodologias utilizadas, incluem-se a abordagem experimental $(n=8)^{(16,18,20,23,26,31,34-35)}$, quase experimentos $(n=2)^{(19,29)}$, estudos preliminares $(n=2)^{(25,32)}$, estudo de grupo único $(n=2)^{(17,33)}$, exploratório $(n=1)^{(21)}$, estudo clínico randomizado $(n=1)^{(22)}$, estudo de caso $(n=1)^{(24)}$, relato de caso $(n=1)^{(28)}$, estudo controlado $(n=1)^{(27)}$ e cross-over $(n=1)^{(30)}$. Embora somente um estudo apresentasse abordagem qualitativa ${ }^{(28)}$, quatro pesquisas quantitativas analisaram as intervenções por meio de avaliação subjetiva da percepção das crianças( ${ }^{(29)}$, dos pais ${ }^{(20)}$, dos profissionais de saúde ${ }^{(33)}$ e das crianças e dos seus professores em conjunto ${ }^{(30)}$.

As intervenções ocorreram em diferentes cenários, tais como laboratório $(n=7)^{(16,18-19,22-24)}$, ambulatório $^{(21,29,31,34-35)}(\mathrm{n}=4)$, playgrounds ${ }^{(33)}$, escola $(\mathrm{n}=2)^{(25,30)}$ e domicílio $(\mathrm{n}=1)^{(28)}$. Em quatro estudos ${ }^{(17,20,27,32)}$ incluídos, os autores não reportaram os locais de desenvolvimento das intervenções. 
No que se refere à população, seis artigos discriminaram o tipo de PC dos participantes, a saber: hemiplégica $(n=2)^{(26,34)}$, diparética $(n=3)^{(23,31,35)}$, hemiplégica e diparética $(n=1)^{(25)}$ e tetraplégica espática $(n=1)^{(28)}$. O número mínimo de participantes foi de um e o máximo de 48, com idades variando entre 21 meses e 12 anos. Quatorze estudos consideraram meninos e meninas(16-18,21-22,25-31,33,34-35), cinco incluíram somente meninos $^{(19,23,24,28,32)}$ e um teve como participantes apenas meninas ${ }^{(20)}$.

O Quadro 4 ilustra os aspectos abordados no processo de reabilitação de crianças com PC, utilizando o lúdico como propósito para o estímulo motor. Grande parte dos estudos utilizou videogames e jogos de computador $(n=9)^{(21-23,25-26,29-31,34)}$. Foram utilizados também, como intervenção lúdica, robôs $(n=5)^{(16-17,24,30,32)}$, animais (cavalo) $(n=1)^{(20)}$, carrinhos de brinquedo adaptados $(n=1)^{(28)}$, equipamentos interativos $(n=2)^{(19,28)}$, jogos de alcançar, agarrar e de encaixes, de acordo com o interesse da criança $(n=2)^{(19,35)}$, e brincadeiras em playground $(n=1)^{(33)}$.

Figura 1: Fluxograma PRISMA do processo de busca na literatura.

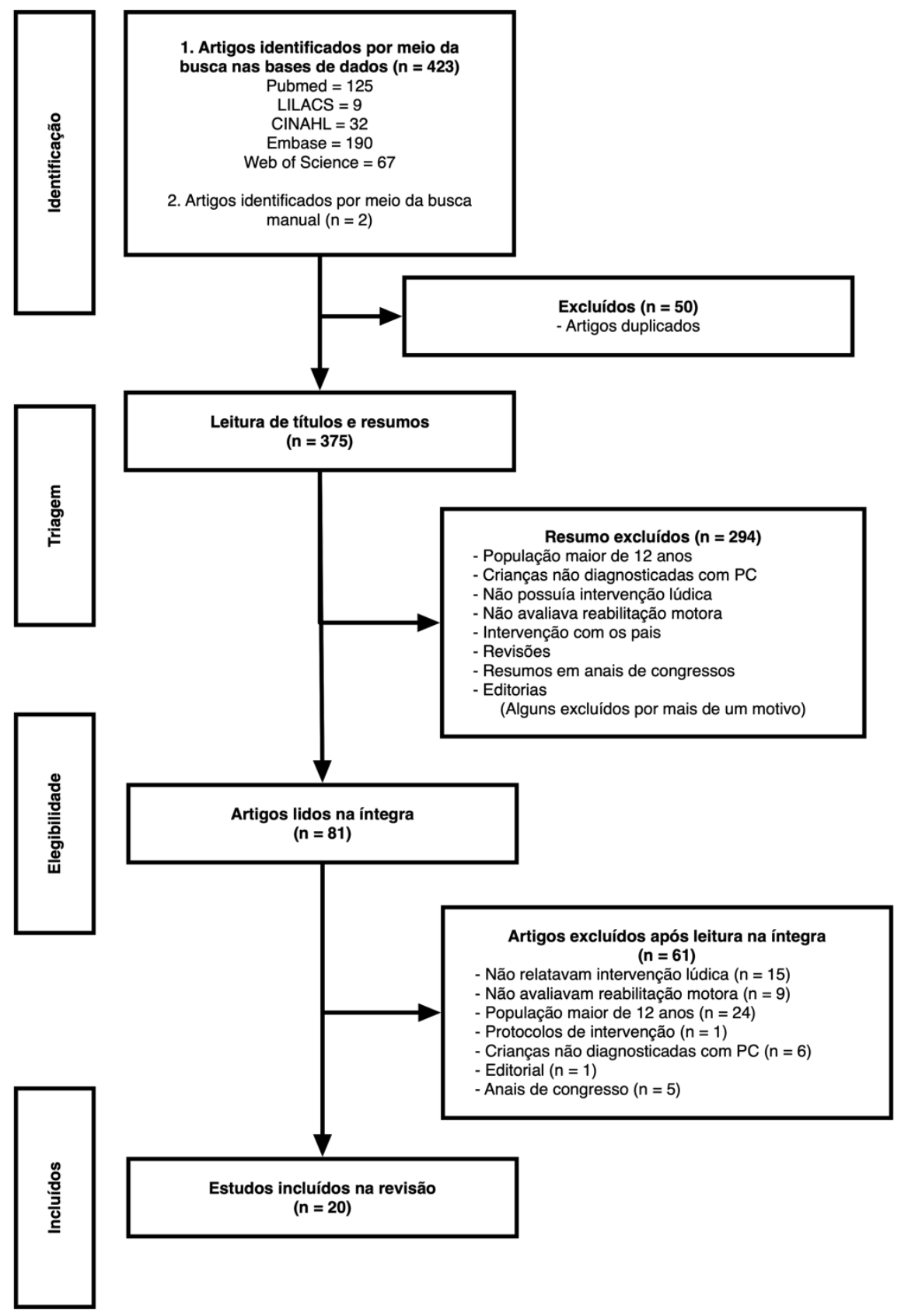


Quadro 3: Principais características dos estudos incluídos.

\begin{tabular}{|c|c|c|c|c|c|}
\hline $\begin{array}{l}\text { Primeiro } \\
\text { autor, ano }\end{array}$ & Objetivo relacionado à função motora & Tipo de estudo & $\begin{array}{l}\text { Contexto da } \\
\text { intervenção }\end{array}$ & População e amostra & Idade e sexo \\
\hline $\begin{array}{l}\text { CHEN, } \\
2007^{(16)}\end{array}$ & $\begin{array}{l}\text { Investigar os efeitos de treinamentos de Realidade Virtual na intervenção de } \\
\text { comportamento em crianças com PC espástica. }\end{array}$ & Experimental & $\begin{array}{l}\text { Laboratório de } \\
\text { fisioterapia }\end{array}$ & $\begin{array}{l}\text { Diagnóstico de PC, tipo não } \\
\text { reportado } \\
\mathrm{N}=4\end{array}$ & $\begin{array}{l}4 \text { a } 8 \text { anos } \\
\text { Meninos e } \\
\text { meninas }\end{array}$ \\
\hline $\begin{array}{l}\text { FASOLI, } \\
2008^{(17)}\end{array}$ & $\begin{array}{l}\text { Examinar a viabilidade e os efeitos da terapia robótica do membro superior para } \\
\qquad \text { crianças com PC hemiplégica. }\end{array}$ & Grupo único & Não reportado & $\begin{array}{l}\text { Diagnóstico de } \mathrm{PC} \text {, tipo não } \\
\text { reportado } \\
\mathrm{N}=12\end{array}$ & $\begin{array}{l}5 \text { a } 12 \text { anos } \\
\text { Meninos e } \\
\text { meninas }\end{array}$ \\
\hline $\begin{array}{l}\text { CRAJÉ, } \\
2010^{(18)}\end{array}$ & $\begin{array}{l}\text { Investigar o planejamento de ação em crianças pequenas (3 a } 6 \text { anos), com e sem } \\
\text { PC unilateral. }\end{array}$ & $\begin{array}{l}\text { Exploratório } \\
\text { experimental }\end{array}$ & $\begin{array}{l}\text { Laboratório da } \\
\text { universidade }\end{array}$ & $\begin{array}{l}\text { Diagnóstico de PC, tipo não } \\
\text { reportado } \\
\mathrm{N}=24\end{array}$ & $\begin{array}{l}3 \text { a } 6 \text { anos } \\
\text { Meninos e } \\
\text { meninas }\end{array}$ \\
\hline $\begin{array}{l}\text { AARTS, } \\
2011^{(19)}\end{array}$ & $\begin{array}{l}\text { Descrever um protocolo de terapia de movimento induzido por restrições } \\
\text { modificadas para crianças combinado com o treinamento bimanual específico de } \\
\text { tarefa orientado por objetivo. }\end{array}$ & $\begin{array}{c}\text { Quase } \\
\text { experimental }\end{array}$ & $\begin{array}{l}\text { Laboratório da } \\
\text { universidade }\end{array}$ & $\begin{array}{l}\text { Diagnóstico de } \mathrm{PC} \text {, tipo não } \\
\text { reportado } \\
\mathrm{N}=1\end{array}$ & $\begin{array}{l}2,7 \text { anos } \\
\text { Menino }\end{array}$ \\
\hline $\begin{array}{l}\text { FRANK, } \\
2011^{(20)}\end{array}$ & $\begin{array}{l}\text { Descrever a melhoria da função como a participação medida pela percepção de } \\
\text { autocompetência e aceitação social. }\end{array}$ & Experimental & Não reportado & $\begin{array}{l}\text { Diagnóstico de } P C \text {, tipo não } \\
\text { reportado } \\
\mathrm{N}=1\end{array}$ & $\begin{array}{l}6 \text { anos } \\
\text { Menina }\end{array}$ \\
\hline $\begin{array}{l}\text { GORDON, } \\
2012^{(21)}\end{array}$ & $\begin{array}{l}\text { Explorar a possibilidade de usar o Nintendo } \mathrm{Wii}^{\mathrm{TM}} \text { como ferramenta de reabilitação } \\
\text { para crianças com PC em um país em desenvolvimento e determinar o impacto na } \\
\text { função motora bruta. }\end{array}$ & $\begin{array}{l}\text { Clínico- } \\
\text { exploratório }\end{array}$ & Ambulatório & $\begin{array}{l}\text { Diagnóstico de } \mathrm{PC} \text {, tipo não } \\
\text { reportado } \\
\mathrm{n}=7\end{array}$ & $\begin{array}{l}6 \text { a } 12 \text { anos } \\
\text { Meninos e } \\
\text { meninas }\end{array}$ \\
\hline $\begin{array}{l}\text { SHARAN, } \\
2012^{(22)}\end{array}$ & $\begin{array}{l}\text { Avaliar o efeito do treinamento da realidade virtual em termos de equilíbrio, } \\
\text { capacidade manual, nível de participação e satisfação entre as crianças pós- } \\
\text { operacionais, que sofrem de PC e que passaram por processo de reabilitação. }\end{array}$ & $\begin{array}{l}\text { Clínico- } \\
\text { randomizado }\end{array}$ & $\begin{array}{l}\text { Laboratório da } \\
\text { universidade }\end{array}$ & $\begin{array}{c}\text { Diagnóstico de } \mathrm{PC} \text {, tipo não } \\
\text { reportado } \\
\mathrm{n}=16 \\
\text { ( } \mathrm{N}=8 \text { no grupo experimental e } \\
\mathrm{n}=8 \text { no grupo controle) }\end{array}$ & $\begin{array}{l}8 \text { a } 10 \text { anos } \\
\text { Meninos e } \\
\text { meninas }\end{array}$ \\
\hline $\begin{array}{l}\text { BARTON, } \\
2013^{(23)}\end{array}$ & $\begin{array}{l}\text { Examinar a mudança do acoplamento da pelve em um jogo de computador } \\
\text { conduzido por rotações pélvicas. }\end{array}$ & Experimental & $\begin{array}{l}\text { Laboratório da } \\
\text { universidade }\end{array}$ & $\begin{array}{l}\text { Crianças com PC do tipo } \\
\text { diparética } \\
\mathrm{N}=1\end{array}$ & $\begin{array}{l}10 \text { anos } \\
\text { Menino }\end{array}$ \\
\hline $\begin{array}{l}\text { BURDEA, } \\
2013^{(24)}\end{array}$ & $\begin{array}{l}\text { Investigar a viabilidade do treinamento robótico baseado no jogo do tornozelo em } \\
\text { crianças com PC. }\end{array}$ & Estudo de Caso & $\begin{array}{l}\text { Laboratório da } \\
\text { universidade }\end{array}$ & $\begin{array}{l}\text { Diagnóstico de } \mathrm{PC} \text {, tipo não } \\
\text { reportado } \\
\mathrm{n}=3\end{array}$ & $\begin{array}{c}7 \text { a } 12 \text { anos } \\
\text { Meninos }\end{array}$ \\
\hline $\begin{array}{l}\text { LUNA-OLIVA, } \\
2013^{(25)}\end{array}$ & $\begin{array}{l}\text { Avaliar a utilidade de um sistema de videogame baseado em tecnologia de } \\
\text { realidade virtual não imersiva (Xbox } 360 \text { kinect }^{\mathrm{TM}} \text { ) para apoiar o tratamento } \\
\text { convencional de fisioterapia de crianças com PC. }\end{array}$ & Estudo preliminar & Escola & $\begin{array}{l}\text { Crianças com PC leve- } \\
\text { moderada hemiplégica e } \\
\text { diplégica } \\
\mathrm{N}=11\end{array}$ & $\begin{array}{c}4 \text { a } 12 \text { anos } \\
\text { Meninos e } \\
\text { meninas }\end{array}$ \\
\hline
\end{tabular}




\begin{tabular}{|c|c|c|c|c|c|}
\hline $\begin{array}{l}\text { Primeiro } \\
\text { autor, ano }\end{array}$ & Objetivo relacionado à função motora & Tipo de estudo & $\begin{array}{l}\text { Contexto da } \\
\text { intervenção }\end{array}$ & População e amostra & Idade e sexo \\
\hline $\begin{array}{l}\text { peper, } \\
2013^{(26)}\end{array}$ & $\begin{array}{l}\text { Examinar os efeitos potenciais do treinamento sobre coordenação bimanual no } \\
\text { desempenho do braço afetado. }\end{array}$ & Experimental & $\begin{array}{l}\text { Laboratório da } \\
\text { universidade }\end{array}$ & $\begin{array}{l}\text { Crianças com PC hemiparética } \\
\qquad \mathrm{N}=6\end{array}$ & $\begin{array}{l}7 \text { a } 12 \text { anos } \\
\text { Meninos e } \\
\text { meninas }\end{array}$ \\
\hline $\begin{array}{l}\text { CURTIS, } \\
2014(27)\end{array}$ & $\begin{array}{l}\text { Estudar o efeito do estiramento ativo dos flexores plantares do tornozelo usando } \\
\text { um stander dinâmico em crianças com PC. }\end{array}$ & Estudo controlado & Não reportado & $\begin{array}{l}\text { Crianças com PC nível I a III } \\
\qquad \mathrm{N}=6\end{array}$ & $\begin{array}{l}4 \text { a } 11 \text { anos } \\
\text { Meninos e } \\
\text { meninas }\end{array}$ \\
\hline $\begin{array}{l}\text { HUANG, } \\
2014^{(28)}\end{array}$ & $\begin{array}{c}\text { Selecionar um conjunto de variáveis que quantificam as mudanças na mobilidade } \\
\text { independente, socialização e autocuidado, avaliadas qualitativamente pelos } \\
\text { pesquisadores. }\end{array}$ & Relato de caso & $\begin{array}{l}\text { Domicílio do } \\
\text { participante }\end{array}$ & $\begin{array}{l}\text { Criança com PC tetraplégica } \\
\text { espástica } \\
\mathrm{N}=1\end{array}$ & $\begin{array}{l}21 \text { meses } \\
\text { Menino }\end{array}$ \\
\hline $\mathrm{NI}, 2014^{(29)}$ & $\begin{array}{l}\text { Descrever o desenho e a avaliação de dois jogos de computador destinados a } \\
\text { verificar a relevância terapêutica e experiência de jogo para reabilitação de } \\
\text { membros inferiores e superiores de crianças com PC. }\end{array}$ & $\begin{array}{l}\text { Quase } \\
\text { experimental }\end{array}$ & Ambulatório & $\begin{array}{l}\text { Diagnóstico de } \mathrm{PC} \text {, tipo não } \\
\text { reportado } \\
\mathrm{N}=8\end{array}$ & $\begin{array}{l}10 \text { anos } \\
(\mathrm{DP}=1,4 \text { anos }) \\
\text { Meninos e } \\
\text { meninas }\end{array}$ \\
\hline $\begin{array}{l}\text { PRESTON, } \\
2014(30)\end{array}$ & $\begin{array}{c}\text { Apresentar a viabilidade de implantação do sistema de jogos de reabilitação de } \\
\text { braço assistida por computador para escolas inglesas com o objetivo de envolver } \\
\text { crianças com PC de } 5 \text { a } 12 \text { anos de idade em exercícios diários de reabilitação de } \\
\text { braço durante a semana escolar. }\end{array}$ & $\begin{array}{l}\text { Cross-over design } \\
\qquad(\mathrm{AB}-\mathrm{BA})\end{array}$ & Escola & $\begin{array}{l}\text { Crianças com } \mathrm{PC} \text {, com } \\
\text { comprometimento nos } \\
\text { membros superiores } \\
\mathrm{N}=11\end{array}$ & $\begin{array}{l}5 \text { a } 12 \text { anos } \\
\text { Meninos e } \\
\text { meninas }\end{array}$ \\
\hline $\begin{array}{l}\text { ALSAIF, } \\
2015^{(31)}\end{array}$ & $\begin{array}{l}\text { Investigar o efeito do treinamento com os jogos Nintendo Wii Fit no desempenho } \\
\text { motor de crianças com PC espástica. }\end{array}$ & Experimental & Ambulatório & $\begin{array}{l}\text { Crianças com PC diparética } \\
\qquad \mathrm{N}=40\end{array}$ & $\begin{array}{l}6 \text { a } 10 \text { anos } \\
\text { Meninos e } \\
\text { meninas }\end{array}$ \\
\hline $\begin{array}{l}\text { TONG, } \\
2015^{(32)}\end{array}$ & $\begin{array}{l}\text { Apresentar estudo preliminar de avaliação do reachMAN's modular handle para } \\
\text { treinar a função dos membros superiores. }\end{array}$ & Estudo preliminar & Não reportado & $\begin{array}{l}\text { Diagnóstico de } \mathrm{PC} \text {, tipo não } \\
\text { reportado } \\
\mathrm{N}=1\end{array}$ & $\begin{array}{l}8 \text { anos } \\
\text { Menino }\end{array}$ \\
\hline $\begin{array}{l}\text { PRATT, } \\
2016^{(33)}\end{array}$ & $\begin{array}{l}\text { Investigar o efeito de playgrounds de acordo com a Lei dos Americanos com } \\
\text { Deficiências e de playgrounds em desacordo com essa lei nas atividades físicas } \\
\text { com crianças portadoras de PC. }\end{array}$ & $\begin{array}{l}\text { Pesquisa de grupo } \\
\text { único }\end{array}$ & Playgrounds & $\begin{array}{l}\text { Crianças com PC nível II } \\
\qquad \mathrm{n}=5\end{array}$ & $\begin{array}{l}6 \text { a } 10 \text { anos } \\
\text { Meninos e } \\
\text { meninas }\end{array}$ \\
\hline DO, 2016(34) & $\begin{array}{l}\text { Verificar se o exercício de membros superiores baseado na realidade virtual é } \\
\text { efetivo para a melhora das funções das extremidades superiores afetadas nas } \\
\text { crianças com PC hemiplégica e a capacidade de coordenação bilateral das mãos. }\end{array}$ & $\begin{array}{l}\text { Experimento com } \\
\text { desenho tipo } A B A\end{array}$ & Ambulatório & $\begin{array}{l}\text { Crianças com PC hemiplégica } \\
\qquad \mathrm{N}=3\end{array}$ & $\begin{array}{l}5 \text { a } 7 \text { anos } \\
\text { Meninos e } \\
\text { meninas }\end{array}$ \\
\hline $\begin{array}{l}\text { SENAPATI, } \\
2017^{(35)}\end{array}$ & $\begin{array}{l}\text { Comparar a eficácia das atividades de jogo de tabuleiro e atividades funcionais de } \\
\text { motricidade fina em crianças com PC diplégica espástica. }\end{array}$ & Experimental & $\begin{array}{l}\text { departamento de } \\
\text { terapia ocupacional }\end{array}$ & $\begin{array}{l}\text { Crianças com PC diparética } \\
\qquad N=24\end{array}$ & $\begin{array}{l}61,2 \text { a } 62,9 \\
\text { meses } \\
\text { Meninos e } \\
\text { meninas }\end{array}$ \\
\hline
\end{tabular}


Quadro 4: Identificação do estudo e detalhamento da intervenção lúdica desenvolvida; variáveis/ferramentas de mensuração e principais resultados.

\begin{tabular}{|c|c|c|c|c|}
\hline $\begin{array}{l}\text { Primeiro } \\
\text { autor, ano }\end{array}$ & Intervenção lúdica e seu formato & $\begin{array}{c}\text { Duração, número e tempo } \\
\text { das sessões }\end{array}$ & $\begin{array}{l}\text { Variáveis e ferramentas de } \\
\text { avaliação }\end{array}$ & Principais resultados \\
\hline $\begin{array}{l}\text { CHEN, } \\
2007^{(16)}\end{array}$ & $\begin{array}{l}\text { Jogo com realidade virtual. } \\
\text { As crianças estavam sentadas em uma } \\
\text { cadeira especial com apoio para tronco } \\
\text { durante a intervenção. Os programas de } \\
\text { realidade virtual foram selecionados com } \\
\text { base nas habilidades motoras e de cognição } \\
\text { das crianças. }\end{array}$ & $\begin{array}{l}4 \text { semanas de duração } \\
\mathrm{n}^{\circ} \text { de sessões não reportado } \\
30 \text { minutos cada }\end{array}$ & $\begin{array}{l}\text { Motricidade motora fina } \\
\text { - Peabody Developmental } \\
\text { Motor Scales-Second Edition } \\
\text { (PDMS- 2) - Subteste }\end{array}$ & $\begin{array}{l}\text { Com relação às quatro crianças avaliadas, no subteste de } \\
\text { avaliação motora fina (agarrar), duas apresentaram melhora: as } \\
\text { crianças } 2 \text { e } 4 \text { (ambas com } 48 \text { pontos na avaliação e } 51 \text { pontos na } \\
\text { reavaliação). No subteste de avaliação visomotora, três crianças } \\
\text { obtiveram aumento na pontuação durante a reavaliação: a } \\
\text { criança } 1 \text { (95 pontos na avaliação e } 106 \text { pontos na reavaliação), a } \\
\text { criança } 3 \text { ( } 114 \text { pontos na avaliação e } 119 \text { pontos na reavaliação) e } \\
\text { a criança } 4 \text { (137 pontos na avaliação e } 140 \text { pontos na reavaliação. } \\
\text { No subteste de lateralidade, todas obtiveram melhora: a criança } \\
1 \text { (141 na avaliação e } 153 \text { pontos para a reavaliação), a criança } 2 \\
\text { (192 pontos na avaliação e } 193 \text { pontos na reavaliação), a criança } \\
3 \text { (141 na avaliação e } 153 \text { pontos para a reavaliação) e a criança } 4 \\
\text { (188 pontos na avaliação e } 191 \text { pontos na reavaliação). }\end{array}$ \\
\hline $\begin{array}{l}\text { FASOLI, } \\
2008^{(17)}\end{array}$ & $\begin{array}{l}\text { Protótipo robótico. } \\
640 \text { movimentos repetitivos, com o braço } \\
\text { parético durante cada sessão. Foram } \\
\text { realizados, principalmente, movimentos } \\
\text { com as articulações do ombro e do } \\
\text { cotovelo. }\end{array}$ & $\begin{array}{l}8 \text { semanas de duração } \\
16 \text { sessões } \\
60 \text { minutos cada }\end{array}$ & $\begin{array}{l}\text { - QUEST: Testes de Habilidades } \\
\text { - Fugl-Meyer: Subteste de } \\
\text { avaliação do membro superior }\end{array}$ & $\begin{array}{c}\text { No teste de habilidades, os participantes avaliados obtiveram } \\
\text { melhora significativa na dissociação de movimento }(p<0,0005) \text {. } \\
\text { Na avaliação do subteste de membro superior, a melhora } \\
\text { também foi significativa }(p<0,0005) \text {. }\end{array}$ \\
\hline $\begin{array}{l}\text { CRAJÉ } \\
2010^{(18)}\end{array}$ & $\begin{array}{l}\text { Acertar uma espada de madeira em um } \\
\text { buraco apertado em um bloco de madeira. } \\
\text { A criança manteve-se na própria cadeira } \\
\text { ajustada, de tal modo que os pés estavam } \\
\text { apoiados e ela poderia descansar as axilas } \\
\text { na mesa. Uma espada de madeira foi } \\
\text { deixada sobre a mesa e teve que ser } \\
\text { colocada em um orifício apertado em um } \\
\text { bloco de madeira. }\end{array}$ & $\begin{array}{l}6 \text { semanas de terapia de } \\
\text { movimento induzida por } \\
\text { restrições (TMIR), seguido de } \\
2 \text { semanas de treinamento } \\
\text { bimanual (TBi). } \\
\mathrm{n}^{\circ} \text { de sessões não foi } \\
\text { reportado. } \\
10 \text { minutos cada }\end{array}$ & $\begin{array}{l}\text { Condições críticas e posturas } \\
\text { finais confortáveis }\end{array}$ & $\begin{array}{l}\text { As crianças submetidas às intervenções em posturas finas } \\
\text { confortáveis obtiveram resultados significantes, sendo estes } \\
\text { maiores no grupo controle }(p<0,001) \text {. }\end{array}$ \\
\hline $\begin{array}{l}\text { AARTS, } \\
2011^{(19)}\end{array}$ & $\begin{array}{l}\text { Jogos de alcançar, agarrar e de encaixes de } \\
\text { acordo com o interesse da criança. } \\
\text { Terapia de constrição utilizando } \\
\text { movimentos de seu braço esquerdo com } \\
\text { jogos que exigiram repetição suficiente dos } \\
\text { comportamentos motores. }\end{array}$ & $\begin{array}{l}9 \text { semanas de atendimento, } \\
\text { com follow up no } 17^{\circ} \text { dia, } \\
\text { após o término das sessões. } \\
\mathrm{n}^{\circ} \text { e tempo das sessões não } \\
\text { foram reportados. }\end{array}$ & $\begin{array}{l}\text { ABILHAND-Kids - } \\
\text { Comprometimento dos } \\
\text { membros superiores } \\
\text { Hand Assessment (AHA) - } \\
\text { Avaliação funcional de } \\
\text { membros superiores }\end{array}$ & $\begin{array}{l}\text { Na avaliação funcional dos membros superiores, o participante } \\
\text { atingiu } 44 \% \text { da pontuação total das escalas avaliativas e, na } \\
\text { reavaliação, o valor obtido foi de } 59 \% \text {. Obteve-se melhora de } \\
\text { 15\% na avaliação de membros superiores após a intervenção } \\
\text { lúdica. }\end{array}$ \\
\hline
\end{tabular}




\begin{tabular}{|c|c|c|c|c|}
\hline $\begin{array}{l}\text { Primeiro } \\
\text { autor, ano }\end{array}$ & Intervenção lúdica e seu formato & $\begin{array}{c}\text { Duração, número e tempo } \\
\text { das sessões }\end{array}$ & $\begin{array}{c}\text { Variáveis e ferramentas de } \\
\text { avaliação }\end{array}$ & Principais resultados \\
\hline $\begin{array}{l}\text { FRANK, } \\
2011^{(20)}\end{array}$ & $\begin{array}{l}\text { Cavalo. } \\
\text { Sessão convencional de hipoterapia. }\end{array}$ & $\begin{array}{l}8 \text { semanas de duração. } \\
\mathrm{n}^{\circ} \text { de sessões não reportado. } \\
\text { Cada sessão durou } 45 \\
\text { minutos com a equoterapia, } \\
\text { somada a } 10 \text { minutos de } \\
\text { fisioterapia terrestre e mais } 5 \\
\text { minutos de orientação aos } \\
\text { pais. }\end{array}$ & $\begin{array}{l}\text { Avaliação motora grossa - } \\
\text { Medida da Função Motora } \\
\text { Grossa (GMFM 66) }\end{array}$ & $\begin{array}{l}\text { A avaliação basal do GMFM } 66 \text { foi de 96,05. Após a intervenção, } \\
\text { o participante pontuou 97,06, obtendo melhora não significativa } \\
\text { na avaliação da função motora grossa. }\end{array}$ \\
\hline $\begin{array}{l}\text { GORDON, } \\
2012^{(21)}\end{array}$ & $\begin{array}{l}\text { Videogame NIINTENDO WII (jogos: boxe, } \\
\text { tênis e basebol). } \\
\text { Os participantes realizavam o jogo de } \\
\text { acordo com os comandos do mesmo. As } \\
\text { crianças que dependiam de cadeira de } \\
\text { rodas jogavam sentadas e as que } \\
\text { deambulavam jogavam em pé. }\end{array}$ & $\begin{array}{l}6 \text { semanas de duração. } \\
12 \text { sessões } \\
45 \text { minutos cada }\end{array}$ & $\begin{array}{l}\text { Avaliação motora grossa - } \\
\text { GMFM }\end{array}$ & $\begin{array}{l}\text { Com base na avaliação do GMFM, os participantes apresentaram } \\
\text { aumento médio de } 7 \% \text { após a intervenção, sendo as principais } \\
\text { modificações ocorridas nos Itens A, com melhora de } 2 \% \text { (rolar e } \\
\text { sentar) e no item B, com melhora de } 12 \% \text { (sedestação). }\end{array}$ \\
\hline $\begin{array}{l}\text { SHARAN, } \\
2012^{(22)}\end{array}$ & $\begin{array}{l}\text { Videogame NIINTENDO WII (jogos: tênis, } \\
\text { basebol, golfe, boliche e boxe). } \\
\text { Os sujeitos foram designados para jogar os } \\
\text { jogos de acordo com as orientações do } \\
\text { terapeuta. }\end{array}$ & $\begin{array}{l}3 \text { semanas de duração } \\
9 \text { sessões } \\
\text { Tempo das sessões não } \\
\text { reportado. }\end{array}$ & $\begin{array}{l}\text { Função do membro superior - } \\
\text { Sistema de classificação de } \\
\text { habilidade manual (SCHM) } \\
\text { Equilíbrio - pontuação de } \\
\text { equilíbrio pediátrico (PSB) } \\
\text { Psychological Services Bureau } \\
\text { para o equilíbrio. }\end{array}$ & $\begin{array}{l}\text { Houve melhora significativa na avaliação dos grupos } \\
\text { experimental }(p<0,001) \text { e controle }(p<0,001) \text { no índice de PSB } \\
\text { após a intervenção. Também houve melhora significativa da } \\
\text { capacidade manual após a intervenção para ambos os grupos } \\
\text { (experimental }(p<0,05) \text {; controle }(p<0,01)) \text {. }\end{array}$ \\
\hline $\begin{array}{l}\text { BARTON, } \\
2013^{(23)}\end{array}$ & $\begin{array}{l}\text { Jogo de computador. } \\
\text { O objetivo era estourar balões em uma } \\
\text { caverna. Controlava-se a velocidade de } \\
\text { caminhada virtual pelo software do jogo e } \\
\text { também pelo movimento da pelve na } \\
\text { postura ajoelhada. }\end{array}$ & $\begin{array}{l}6 \text { semanas de duração } \\
13 \text { sessões } \\
30 \text { minutos cada }\end{array}$ & $\begin{array}{l}\text { Acoplamento tronco e pelve - } \\
\text { CONVHULL em MATLAB }\end{array}$ & $\begin{array}{c}\text { Durante todas as sessões realizadas e analisadas } \\
\text { biomecanicamente, o teste t pareado mostrou que o } \\
\text { acoplamento do quadril, durante os jogos com alvos distantes, } \\
\text { apresentou-se maior que os jogos com alvos próximos ( } \mathrm{p}= \\
0,007) \text {. }\end{array}$ \\
\hline
\end{tabular}




\begin{tabular}{|c|c|c|c|c|}
\hline $\begin{array}{l}\text { Primeiro } \\
\text { autor, ano }\end{array}$ & Intervenção lúdica e seu formato & $\begin{array}{c}\text { Duração, número e tempo } \\
\text { das sessões }\end{array}$ & $\begin{array}{l}\text { Variáveis e ferramentas de } \\
\text { avaliação }\end{array}$ & Principais resultados \\
\hline $\begin{array}{l}\text { BURDEA, } \\
2013^{(24)}\end{array}$ & $\begin{array}{l}\text { Pequeno protótipo de robô, composto por } \\
\text { uma plataforma pneumática, interligada } \\
\text { entre o pé e o monitor. } \\
\text { O participante pilotou um avião virtual, } \\
\text { atravessando alvos (colinas e vales). No } \\
\text { início do exercício, o terapeuta escolheu a } \\
\text { velocidade do avião, a resistência do ar, a } \\
\text { turbulência, a visibilidade da cena e o } \\
\text { tempo de exercício. }\end{array}$ & $\begin{array}{l}12 \text { semanas de duração } \\
36 \text { sessões } \\
\text { Tempo de cada sessão não } \\
\text { reportado. }\end{array}$ & $\begin{array}{c}\text { Função Motora Grossa - } \\
\text { GMFM }\end{array}$ & $\begin{array}{c}\text { De acordo com a avaliação do GMFM, apenas os participantes } 2 \\
\text { e } 3 \text { obtiveram melhora de } 5,1 \% \text { e } 7,7 \% \text {, respectivamente, na } \\
\text { função motora grossa. }\end{array}$ \\
\hline $\begin{array}{l}\text { LUNA- } \\
\text { OLIVA, } \\
2013^{(25)}\end{array}$ & $\begin{array}{c}\text { Videogame } X \text {-Box } 360 \text { (jogos de futebol, } \\
\text { vôlei, boliche, para dirigir carros e de } \\
\text { aventuras na Disney). } \\
\text { Os jogos tinham um avatar da criança, a } \\
\text { partir do qual ela simulava os movimentos, } \\
\text { obtendo retorno sobre cada tarefa } \\
\text { realizada. }\end{array}$ & $\begin{array}{l}2 \text { meses de duração } \\
2 \text { dias por semana } \\
20 \text { minutos cada }\end{array}$ & $\begin{array}{c}\text { Habilidades motoras - } \\
\text { Assessment of Motor and } \\
\text { Process Skills (AMPS). } \\
\text { Equilíbrio - Pediatric Reach test } \\
\text { (PRT) } \\
\text { Velocidade da marcha - 10- } \\
\text { meters walk test } \\
\text { Avaliação motora grossa - } \\
\text { GMFM }\end{array}$ & $\begin{array}{l}\text { O teste de Friedman mostrou diferenças significativas durante as } \\
\text { reavaliações de todos os testes: motor AMPS }(p=0,001) \text {, } \\
\text { processo AMPS }(p<0,010) \text {, PRT }(p=0,005), 10 M W \text { test }(p<0,029) \\
\text { e GMFM }(p<0,001) .\end{array}$ \\
\hline $\begin{array}{l}\text { PEPER, } \\
2013^{(26)}\end{array}$ & $\begin{array}{c}\text { Quatro jogos de computador. } \\
\text { Aparelho com duas alavancas horizontais, } \\
\text { um computador portátil e um } \\
\text { potenciômetro que monitoravam os } \\
\text { movimentos das alavancas. }\end{array}$ & $\begin{array}{l}6 \text { semanas de duração } \\
12 \text { sessões } \\
30 \text { minutos cada }\end{array}$ & $\begin{array}{l}\text { Avaliação funcional de } \\
\text { membros superiores - Hand } \\
\text { Assessment (AHA) }\end{array}$ & $\begin{array}{c}\text { A pontuação das crianças utilizando a escala AHA aumentou, em } \\
\text { média, de } 1 \text { ponto }(D P \pm 1,08) \text { para } 5,8 \text { pontos }(D P \pm 2,3)(p< \\
0,005) .\end{array}$ \\
\hline $\begin{array}{l}\text { CURTIS, } \\
2014^{(27)}\end{array}$ & $\begin{array}{l}\text { Stander dinâmico e interativo (HAPPY } \\
\text { REHAB, InnovaidApS, Aarhus, Denmark). } \\
\text { O equipamento possuía dois pedais } \\
\text { giratórios, que permitiam a plantiflexão e a } \\
\text { dorsiflexão dos tornozelos. Os pedais } \\
\text { giratórios continham sensores de força na } \\
\text { superfície. Os movimentos do tornozelo } \\
\text { eram usados para controlar os jogos de } \\
\text { computador. }\end{array}$ & $\begin{array}{l}10 \text { semanas } \\
\text { Sessões } 5 \text { dias por semana } \\
30 \text { minutos cada }\end{array}$ & $\begin{array}{l}\text { Função Motora Grossa - } \\
\qquad \text { GMFM } \\
\text { - Número de passadas e os } \\
\text { movimentos passivos e ativos } \\
\text { do tornozelo - 10m walk test }\end{array}$ & $\begin{array}{l}\text { Durante a avaliação do GMFM, a pontuação total dos } \\
\text { participantes foi de } 66 \text { pontos e, na reavaliação, } 67 \text { pontos ( } p= \\
\text { 0,048). Durante a avaliação do } 10 m \text { walk test, que avaliou o } \\
\text { número de pisadas, foi encontrada significância somente durante } \\
\text { o movimento de dorsiflexão com o joelho em extensão ( } p= \\
0,026) \text {. }\end{array}$ \\
\hline
\end{tabular}




\begin{tabular}{|c|c|c|c|c|}
\hline $\begin{array}{l}\text { Primeiro } \\
\text { autor, ano }\end{array}$ & Intervenção lúdica e seu formato & $\begin{array}{c}\text { Duração, número e tempo } \\
\text { das sessões }\end{array}$ & $\begin{array}{l}\text { Variáveis e ferramentas de } \\
\text { avaliação }\end{array}$ & Principais resultados \\
\hline $\begin{array}{l}\text { HUANG, } \\
2014^{(28)}\end{array}$ & $\begin{array}{l}\text { Carrinho de brinquedo adaptado. } \\
\text { A família da criança a encorajou } \\
\text { diariamente a utilizar o carrinho de } \\
\text { brinquedo adaptado em diferentes } \\
\text { cenários, assim como seu fisioterapeuta e } \\
\text { pesquisadores. }\end{array}$ & $\begin{array}{l}12 \text { semanas } \\
\text { Sessões } 5 \text { dias por semana } \\
\text { Duração mínima de } 20 \\
\text { minutos cada }\end{array}$ & $\begin{array}{l}\text { A intervenção foi gravada e os } \\
\text { seguintes itens foram avaliados: } \\
\text { mobilidade independente, } \\
\text { mobilidade assistida; } \\
\text { mobilidade do cuidador }\end{array}$ & $\begin{array}{c}\text { Por meio de análise qualitativa, que incluiu a perspectiva dos } \\
\text { pesquisadores e pais, verificou-se que o ato de dirigir o carro de } \\
\text { passeio exigiu e motivou o aumento da amplitude de movimento } \\
\text { e/ou controle ativo. }\end{array}$ \\
\hline $\mathrm{NI}, 2014^{(29)}$ & $\begin{array}{c}\text { Jogos de computador. } \\
\text { A criança jogava durante } 20 \text { minutos, três } \\
\text { vezes, com pausas, sob a supervisão e } \\
\text { orientação do terapeuta. Após cada jogo, a } \\
\text { criança e o terapeuta completaram um } \\
\text { questionário sobre a experiência com o } \\
\text { jogo. }\end{array}$ & $\begin{array}{l}\text { Não reportada a duração do } \\
\text { estudo. } \\
\text { Cada sessão foi realizada em } 1 \\
\text { dia, durante } 1 \text { hora e } 50 \\
\text { minutos }\end{array}$ & $\begin{array}{c}\text { Questionário com a criança- } \\
\text { PACES e } \\
\text { questionário com os } \\
\text { fisioterapeutas - Escala } \\
\text { Usabilidade do Sistema (SUS), } \\
\text { ambos avaliam a aplicabilidade } \\
\text { do jogo. }\end{array}$ & $\begin{array}{l}\text { Crianças e terapeutas concordaram, unanimemente, sobre o } \\
\text { valor terapêutico dos jogos. Os escores médios no PACES foram } \\
\text { altos ( } 6,24 \pm 0,95 \text { na escala de } 7 \text { pontos). A pontuação do SUS } \\
\text { chegou a } 68 \text { pontos em uma escala de } 100 \text { pontos. }\end{array}$ \\
\hline $\begin{array}{c}\text { PRESTON, } \\
2014^{(30)}\end{array}$ & $\begin{array}{l}\text { Reabilitação robótica assistida com jogos } \\
\text { individuais e em grupo. } \\
\text { Grupo A jogava o videogame em dupla com } \\
\text { colegas da escola que não apresentavam PC } \\
\text { e participantes do Grupo B jogavam } \\
\text { sozinhos. }\end{array}$ & $\begin{array}{c}\text { Máximo de } 4 \text { semanas e } \\
\text { mínimo de } 3 . \\
\text { Sessões realizadas todos os } \\
\text { dias letivos da semana, por } 30 \\
\text { minutos, não } \\
\text { necessariamente um uma } \\
\text { única sessão }\end{array}$ & $\begin{array}{l}\text { Habilidade manual de crianças } \\
\text { com PC - ABILHAND-kids } \\
\text { Funcionalidade de Membro } \\
\text { superior - Canadian } \\
\text { occupational performance } \\
\text { measure (COM) }\end{array}$ & $\begin{array}{l}\text { Quando comparadas as pontuações na avaliação e reavaliação, } \\
\text { durante as medidas finais, não foram encontrados valores } \\
\text { significativos (ABILHAND-kids } \mathrm{p}=0,424 \text { e COPM } \mathrm{p}=0.484 \text { ) para os } \\
2 \text { grupos (A e B). }\end{array}$ \\
\hline $\begin{array}{l}\text { ALSAIF, } \\
2015^{(31)}\end{array}$ & $\begin{array}{l}\text { Jogos Nintendo Wii Fit, com jogos que } \\
\text { objetivam equilíbrio e salto. } \\
\text { Cada criança recebeu um Nintendo Wii e } \\
\text { jogos para uso em casa. }\end{array}$ & $\begin{array}{l}12 \text { semanas de duração. } \\
\mathrm{n}^{\circ} \text { e tempo da sessão não } \\
\text { foram reportados. }\end{array}$ & $\begin{array}{l}\text { Desempenho motor - MABC } 2 \\
\text { Coordenação do membro } \\
\text { superior - subteste: (tocar uma } \\
\text { bola enquanto esta balança) - } \\
\text { Bruininks proficiência motora } \\
\text { (BOTMP) } \\
\text { Função motora geral- Teste de } \\
\text { caminhada de um minuto }\end{array}$ & $\begin{array}{l}\text { Os valores obtidos por meio do MABC } 2 \text { aumentaram } \\
\text { significativamente após a intervenção. Além disso, as pontuações } \\
\text { de destreza manual, incluindo apontar e pegar, equilíbrio, teste } \\
\text { de caminhada de um minuto e BOTMP mostraram melhoras } \\
\text { significativas. }\end{array}$ \\
\hline $\begin{array}{l}\text { TONG, } \\
2015^{(32)}\end{array}$ & $\begin{array}{l}\text { Robô com jogo interativo. } \\
\text { A criança ficou sentada na posição vertical, } \\
\text { com o antebraço apoiado em um braço de } \\
\text { cadeira almofadado, segurando o robô. }\end{array}$ & $\begin{array}{l}2 \text { semanas de duração, com } 3 \\
\text { sessões na primeira semana, e } \\
2 \text { sessões na segunda. } \\
\text { Cada sessão ocorreu em cerca } \\
\text { de } 1 \text { hora, com } 2 \text { minutos de } \\
\text { descanso entre as mudanças } \\
\text { de treino. }\end{array}$ & $\begin{array}{l}3 \text { parâmetros foram utilizados } \\
\text { para quantificar os efeitos da } \\
\text { terapia jogo: precisão, tempo } \\
\text { médio e a suavidade dos } \\
\text { movimentos. }\end{array}$ & $\begin{array}{l}\text { Após a intervenção, os participantes obtiveram um aumento de } \\
52 \% \text { na pontuação de precisão e uma diminuição de } 19 \% \text { no } \\
\text { tempo de alcance. O pico de velocidade e velocidade média } \\
\text { diminuíram } 50 \% \text { e } 30 \% \text {, respectivamente. }\end{array}$ \\
\hline
\end{tabular}




\begin{tabular}{|c|c|c|c|c|}
\hline $\begin{array}{l}\text { Primeiro } \\
\text { autor, ano }\end{array}$ & Intervenção lúdica e seu formato & $\begin{array}{l}\text { Duração, número e tempo } \\
\text { das sessões }\end{array}$ & $\begin{array}{c}\text { Variáveis e ferramentas de } \\
\text { avaliação }\end{array}$ & Principais resultados \\
\hline $\begin{array}{l}\text { PRATT, } \\
\text { 2016(33) }\end{array}$ & $\begin{array}{l}\text { Brincadeiras em Playground. } \\
\text { Dois playgrounds, um seguindo a lei dos } \\
\text { americanos com deficiências (ADA) e outro } \\
\text { não, (non-ADA) foram selecionados } \\
\text { próximo à residência dos participantes. }\end{array}$ & $\begin{array}{l}\text { Entre junho e novembro. } \\
22 \text { sessões } \\
30 \text { minutos, com média de } \\
\text { descanso de } 52 \text { minutos }\end{array}$ & Passadas- StepWatch activity & $\begin{array}{l}\text { No playground } A D A \text { (adaptado) e non } A D A \text { (não adaptado), o } \\
\text { número médio de passos foi: participantes } 1 \text { (non- } A D A=515 ; \\
A D A=526), 3 \text { (non- } A D A=550 ; A D A=589 \text { ), } 4 \text { (non- } A D A=561 ; \\
\qquad A D A=657 \text { ) e } 5 \text { (non- } A D A=622 ; A D A=727) .\end{array}$ \\
\hline $\begin{array}{c}\text { DO, } \\
2016^{(34)}\end{array}$ & $\begin{array}{l}\text { Nintendo Wii (jogos de golf, remo, espada e } \\
\text { ciclismo). } \\
\text { Utilizou um monitor e um controle remoto } \\
\text { que detectava os movimentos dos membros } \\
\text { superiores. O controle remoto foi } \\
\text { manuseado com as duas mãos, movendo } \\
\text { um avatar, de acordo com os comandos que } \\
\text { aparecem na tela. }\end{array}$ & $\begin{array}{l}\text { Total de } 20 \text { sessões; } \\
12 \text { sessões de intervenção; } 4 \\
\text { sessões de basal e } 4 \text { sessões } \\
\text { de follow-up. } \\
\text { Realizadas } 2 \text { sessões por } \\
\text { semana, com } 30 \text { minutos } \\
\text { cada, sendo } 15 \text { minutos em } \\
\text { cada jogo }\end{array}$ & $\begin{array}{l}\text { Função motora dos membros } \\
\text { superiores e das mãos - Wolf } \\
\text { Motor } \\
\text { Funcionalidade dos membros } \\
\text { superiores afetados avaliada } \\
\text { por meio de entrevistas com o } \\
\text { Function Pediatric Motor } \\
\text { Activity Log } \\
\text { Avaliação da coordenação } \\
\text { bilateral das mãos por meio de } \\
\text { atividades (jogar bola no aro e } \\
\text { mover caixas) }\end{array}$ & $\begin{array}{l}\text { Os três participantes do estudo obtiveram escores mais altos na } \\
\text { avaliação da função motora em relação à avaliação basal } \\
\text { (participante 1: avaliação basal = 23,9 pontos e reavaliação = } \\
23,9 \text { pontos; participante } 2 \text { : avaliação basal = } 15,5 \text { pontos e } \\
\text { reavaliação = } 20 \text { pontos; participante } 3 \text { : avaliação basal = } 24.4 \\
\text { pontos e reavaliação = } 26,6 \text { pontos) } \\
\text { O participante } 1 \text { obteve } 22 \text { pontos na avaliação basal de sua } \\
\text { função motora e, na reavaliação, } 23,9 \text { pontos. }\end{array}$ \\
\hline $\begin{array}{l}\text { SENAPATI, } \\
2017^{(35)}\end{array}$ & $\begin{array}{l}\text { Jogos de tabuleiro e atividades funcionais } \\
\text { de autocuidado. } \\
\text { As crianças do grupo A, experimental, } \\
\text { participaram de atividades de jogo de } \\
\text { tabuleiro, e as crianças do grupo B de } \\
\text { atividades funcionais de autocuidado, } \\
\text { adequadas à idade }\end{array}$ & $\begin{array}{c}6 \text { semanas } \\
1 \text { hora de intervenção, } 5 \text { vezes } \\
\text { por semana }\end{array}$ & $\begin{array}{c}\text { Motricidade motora fina } \\
\text { - Peabody Developmental } \\
\text { Motor Scales-Second Edition } \\
\text { (PDMS- 2) }\end{array}$ & $\begin{array}{l}\text { O Grupo - A mostrou-se significativamente melhor que o grupo- } \\
\text { B, quando analisado o quoeficiente motor fino. } P=0,002 \text {. }\end{array}$ \\
\hline
\end{tabular}


Com relação aos formatos das intervenções, alguns enfatizaram o estímulo motor de membros superiores $(n=9)^{(16-19,22,26,30,34-35)}$, outros o estímulo motor global $(n=8)^{(20-21,24-25,28-29,31-32)}$, tronco e quadril $(n=1)^{(23)}$, tendo ocorrido também o enfoque na marcha $(n=2)^{(27,33)}$. As ferramentas utilizadas para avaliação motora de membros superiores foram: AHA $(n=2)^{(19,26)}, \operatorname{SCHM}(n=1)^{(22)}, \operatorname{ABILHAND-kids~}(n=2)^{(19,30)}, \operatorname{PRT}(n=1)^{(25)}$ e, para a avaliação de tronco e quadril, a convehull-Mtla $(n=1)^{(23)}$. Na avaliação da motricidade global, optou-se por realizar a análise biomecânica $(n=2)^{(17,28)}, \operatorname{GMFM}(n=5)^{(20-21,24-25,27)}$, PSB $(N=1)^{(22)}$, Observação $(n=2)^{(18,32)}, \operatorname{MABC}-2(N=1)^{(31)}$, PACES

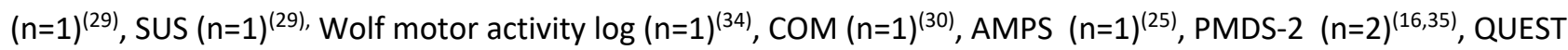
$(n=1)^{(17)}$ e aplicar o questionário de funcionalidade para os pais $(n=1)^{(34)}$. Durante a marcha, as ferramentas avaliativas utilizadas foram o $10 \mathrm{~m}$ walk test $(n=1)^{(33)}$ e o Step watchs activity $(n=1)^{(27)}$.

\section{DISCUSSÃO}

Os resultados dos artigos científicos analisados nesta revisão evidenciam a importância da utilização de abordagens lúdicas como terapia complementar à reabilitação fisioterapêutica, com vistas ao aprimoramento motor e motivacional de crianças com PC.

Dentre as abordagens lúdicas utilizadas nos processos reabilitacionais, destacou-se o jogo de computador utilizando a realidade virtual ( $\mathrm{RV})^{(16-17,22-23,25-26,29,31,34)}$. Trata-se de uma abordagem relativamente recente, pois estudos realizados apenas nos últimos 10 anos verificaram que o uso do lúdico no processo de reabilitação permite simular tarefas funcionais, em complemento às intervenções reabilitatórias convencionais. Esses sistemas, originalmente projetados para recreação, têm sido adaptados por clínicos também para fins terapêuticos. Além disso, alguns jogos de vídeo interativos estão sendo projetados especificamente para a reabilitação ${ }^{(36)}$.

A utilização do Nintendo Wii predominou entre os jogos baseados em RV. O uso de games direcionados ao fortalecimento, condicionamento e à ioga ${ }^{(21,23,25-26,29,31,34)}$ permitiu mensurar os efeitos da terapêutica na funcionalidade e no controle postural de pacientes com disfunção de motricidade grossa. A reabilitação motora utilizando o Nintendo Wii como intervenção lúdica obteve resultados favoráveis no controle postural dos indivíduos analisados, o que pode ser atribuído aos estímulos proporcionados pelo jogo nos sistemas responsáveis pelo controle postural, trabalhando deslocamentos, feedback visual, estímulos proprioceptivos e auditivos que repercutem diretamente no aperfeiçoamento da estabilidade postural|(37).

Vale ressaltar que a estabilidade postural nas crianças com PC tem sido identificada como a principal limitação para o desenvolvimento motor. Manter o controle postural envolve um processo complexo, que depende da integração entre visão, sensação vestibular e periférica, comandos centrais e respostas neuromusculares, os quais interferem nas fases da marcha e, consequentemente, nas atividades funcionais da criança(38).

Os estudos que analisaram playgrounds ${ }^{(33)}$ e brinquedos interativos ${ }^{(19,27-28,35)}$ apresentaram resultados favoráveis na melhora motora ampla e fina de crianças com PC. Apesar do playground ter sido mencionado em um único estudo, trata-se de um espaço onde as crianças pequenas iniciam a sociabilização, interagem entre si, trocam experiências e, muitas vezes, exercitam habilidades motoras ${ }^{(39)}$. Para a criança com PC, foco deste estudo, é importante brincar no playground, ainda que sejam necessárias algumas adaptações para a utilização dos brinquedos, dependendo do comprometimento motor apresentado. Por ser um espaço capaz de estimular 
sobremaneira o desenvolvimento infantil, esta é considerada uma abordagem lúdica eficaz em complemento à reabilitação motora ${ }^{(40)}$

Os brinquedos interativos, de acordo com os propósitos lúdicos para a reabilitação, também constituem boas oportunidades para que as crianças com PC se desenvolvam e iniciem a aprendizagem das regras grupais e sociais $^{(41)}$.

Os estudos analisados investigaram a utilização da abordagem lúdica com ênfase na avaliação, tanto da motricidade fina quanto de habilidades manuais e dos membros superiores ${ }^{(16-17,19,22,26,30-31,34-35)}$ em crianças com PC do tipo hemiparética. Estudos como esses ${ }^{(16-17,19,22,26,30-31,34-35)}$ são necessários, pois requerem certo grau funcional para a execução do jogo, com consequente melhora nas habilidades bimanuais. A reabilitação no paciente neurológico tem sido focada em atividades de repetição e alta intensidade direcionadas à tarefas específicas, por possibilitarem a reaquisição de padrões motores aprendidos ${ }^{(42)}$.

O emprego de robôs no processo de reabilitação também mostrou-se favorável para melhora motora, especificamente de membros superiores de crianças com PC ${ }^{(16-17,24,30,32)}$. Neste caso, os resultados positivos podem ser explicados pela versatilidade da robótica, que permite o treino e a execução de tarefas funcionais ${ }^{(43)}$.

A utilização de animais como estratégia lúdica para crianças com PC foi investigada somente por um dos estudos desta revisão, o qual foi realizado com sujeito único e apresentou melhora durante a avaliação da motricidade ampla(20). Pesquisas sugerem que esses benefícios decorrem da estimulação resultante do movimento tridimensional proporcionado pelo cavalo, por exigir constantes ajustes do praticante, e do fato deste tipo de terapia não ser realizada em ambiente clínico, o que possibilita diferentes estímulos e favorece a reabilitação(44).

Em relação ao tempo de fisioterapia, as sessões variaram de um dia a cinco meses, com frequência de uma a cinco vezes por semana e duração de 10 a 60 minutos cada. Alguns estudos ${ }^{(21-22,31)}$ não reportaram o número de sessões realizadas, mas a literatura recomenda desenvolver quantas forem necessárias para a continuidade do tratamento, até obtenção de melhora global das disfunções musculoesqueléticas ${ }^{(45)}$. Nesse sentido, a utilização do lúdico favorece a adesão ao tratamento fisioterapêutico pediátrico, pois estabelece a funcionalidade da criança para o brincar como um dos objetivos primordiais do plano de tratamento, por ser este um dos principais desejos das crianças e de seus pais ${ }^{(10)}$.

Os artigos incluídos nesta revisão objetivaram contribuir para melhora da motricidade grossa e fina, do equilíbrio, da marcha e da biomecânica corporal em crianças com diagnóstico de PC. Por meio de ferramentas avaliativas específicas, verificou-se a eficácia dos tratamentos descritos. A ferramenta mais utilizada para a avaliação da motricidade grossa foi a escala $\operatorname{GMFM}^{(20-21,24-25,27)}$; para a motricidade fina, a escala $\mathrm{AHA}^{(17,19,24,26)}$; e para avaliação da marcha e biomecânica corporal, as análises cinemáticas e testes de pisadas ${ }^{(27,33)}$.

Os testes aplicados para avaliar crianças com diagnóstico de PC apresentam algumas vantagens (descrever parâmetros motores) e desvantagens (avaliações subjetivas). Assim, o examinador deve escolher aquele mais adequado aos seus objetivos, tanto para fins de pesquisas e triagem clínica quanto para verificação da eficiência da intervenção precoce proposta ${ }^{(46)}$. Além disso, deve estar atento às propriedades psicométricas, pois bons escores de confiabilidade e validade são determinantes na eficácia do teste, principalmente quando aplicados em indivíduos de determinada faixa etária ou com condições clínicas específicas ${ }^{(47)}$. 
Nos estudos analisados, as avaliações e intervenções com as crianças ocorreram principalmente em laboratórios ${ }^{(16,18,23-24,26)}$ e ambulatórios ${ }^{(21,29,31,34-35)}$, o que pode interferir nos resultados, uma vez que não fazem parte do ambiente imediato da criança. Evidências apontam que as respostas motoras mediante a estimulação de crianças (típicas e atípicas) em desenvolvimento ocorrem após processos progressivamente mais complexos e de interações recíprocas entre pessoas, objetos e símbolos no ambiente externo imediato (escola, projeto social, clínicas de reabilitação, entre outros). Dessa forma, essa interação bidimensional influencia na evolução motora, sobretudo entre crianças que apresentam déficits motores decorrentes de lesão neurológica. Em contrapartida, entende-se que o ambiente das avaliações e intervenções foi controlado pela facilidade e credibilidade de espaço, bem como pela presença de equipamentos e profissionais apropriados ${ }^{(48)}$.

Apesar dos artigos mostrarem resultados favoráveis para a reabilitação de crianças com PC por meio de atividades lúdicas, alguns foram obtidos apenas mediante a comparação da pontuação dos participantes nos parâmetros motores de avaliação e de reavaliação(16,19,21,24,29,32-34), não apresentando, portanto, comparação estatística intergrupos com base em um valor de $p$, que descreve a probabilidade dos grupos diferirem apenas por acaso. Além disso, o número de indivíduos incluídos nas pesquisas era, muitas vezes, reduzido, ou até mesmo estudos de sujeito único(16,19-20,23-24,28,32-34).

Em virtude dessas limitações, as conclusões dos estudos analisados, embora importantes, reforçam a necessidade de mais pesquisas sobre o tema. Avaliar o impacto do brincar com um maior número de indivíduos, utilizando metodologias robustas, como os estudos clínicos randomizados, poderá evidenciar com maior precisão se o uso de determinada abordagem lúdica em crianças com PC influencia ou não na sua melhora motora. No entanto, ampliar o número de participantes com PC nos estudos é um desafio, em virtude das especificidades do comprometimento de cada paciente. Isso também dificulta o desenvolvimento de estudos clínicos randomizados ${ }^{(24)}$, devido à falta de grupos homogêneos que atendam aos critérios de elegibilidade, pois, inicialmente, os grupos devem ser semelhantes no que diz respeito aos indicadores de prognóstico mais importantes.

A quantidade limitada de estudos clínicos randomizados nesta revisão e as amostras reduzidas evidenciam essa dificuldade, que implica reunir a melhor evidência disponível sobre o uso de estratégias lúdicas na reabilitação de desordens motoras em crianças com PC. A pertinência desta revisão está em mostrar o estado da arte, com o intuito de não apenas fornecer evidências sobre impacto do brincar na reabilitação motora entre crianças com PC, mas direcionar novos campos de pesquisa. Entende-se que a prática baseada em evidências para a fisioterapia(49), e áreas afins, deve integrar as melhores evidências disponíveis para que cuidados de alta qualidade possam ser prestados. Nesse sentido, os estudos clínicos randomizados são o padrão-ouro dos desenhos experimentais.

\section{CONCLUSÃO}

Considerando-se o universo de artigos que compõem a presente revisão, pode-se afirmar que o brincar é utilizado como meio de favorecer ganhos motores em crianças com PC e contribuir para o processo de reabilitação, uma vez que enfatiza componentes de desempenho necessários à execução de tais atividades. 
Há considerável número de estudos com grupos homogêneos de PC e de crianças portadoras de diferentes tipos de PC e, consequentemente, diversas alterações de desenvolvimento. São também expressivas as pesquisas sobre a interação da criança com o lúdico e a respeito da avaliação motora fina e das habilidades de membros superiores em crianças com PC do tipo hemiparética, por apresentarem alto nível de funcionalidade.

Este estudo reporta as estratégias lúdicas utilizadas com crianças portadoras de PC e suas contribuições para o desenvolvimento motor, com base em investigações de abordagens qualitativa e quantitativa. As estratégias lúdicas mais utilizadas com essas crianças são videogames, jogos de computadores e intervenções com robôs ou protótipos.

Os resultados desta revisão devem ser considerados no contexto de limitações e fortalezas. Embora cinco importantes bases de dados tenham sido consultadas independentemente por dois pesquisadores para o levantamento dos artigos, podem existir outros estudos publicados em revistas não incluídas em tais bases. A avaliação da qualidade metodológica dos estudos incluídos não foi objetivo desta revisão, mas as limitações assinaladas, tais como pequenas amostras, conhecimento dos participantes e do terapeuta que administrou a intervenção, falta de randomização, número e frequência de sessões das intervenções, devem ser consideradas para a interpretação dos resultados apresentados.

Os resultados advindos de estudos quantitativos, que utilizaram instrumentos de avaliação, evidenciaram melhora no quadro motor global dos participantes após as intervenções lúdicas. Apenas um estudo incluído nesta revisão adotou abordagem qualitativa para investigar a percepção dos pais e profissionais de saúde sobre a intervenção. Todavia, alguns estudos quantitativos avaliaram subjetivamente crianças, pais, professores e profissionais de saúde a respeito da intervenção utilizada. Nesse sentido, destaca-se a importância de conhecer a percepção das diversas pessoas envolvidas nas intervenções para a escolha da melhor estratégia a ser utilizada e identificação da necessidade de eventuais adequações em estudos futuros, conforme o contexto e a populaçãoalvo. Particularmente no Brasil, há escassa produção de conhecimentos sobre o brincar de crianças que apresentam deficiências físicas, razão pela qual a maioria dos periódicos destacados nesta revisão é estrangeira.

Considera-se que a presente revisão alcançou os objetivos a que se propôs, pois permitiu vislumbrar a utilização do lúdico nas pesquisas com crianças com PC, em especial, como estratégia complementar de reabilitação. Diante do exposto, recomenda-se a realização de: a) pesquisas que investiguem os efeitos do lúdico, contemplando a heterogeneidade dos tipos de PC; b) pesquisas que analisem os efeitos do uso do brincar virtual para promover o desempenho motor das crianças com PC, a fim de implementar sua utilização na prática clínica.

Esta revisão contribui com informações importantes para subsidiar futuras investigações no âmbito da reabilitação, principalmente de fisioterapia, e demais áreas como a enfermagem, psicologia, fonoaudiologia e pedagogia, para fins de reiterar o uso do lúdico com crianças com PC e o desenvolvimento de novas investigações.

\section{Agradecimentos}

O presente trabalho foi realizado com apoio da Coordenação de Aperfeiçoamento de Pessoal de Nível Superior - Brasil (CAPES) - Código de Financiamento 001 e do Conselho Nacional de Desenvolvimento Científico e Tecnológico (CNPq), Brasil, Processo no 308329/2014-7. 


\section{REFERÊNCIAS}

1. Roque AH, Kanashiro MG, Kazon S, Grecco LAC, Salgado ASI, Oliveira CS. Análise do equilíbrio estático em crianças com paralisia cerebral do tipo diparesia espástica com e sem o uso de órteses. Fisioter. mov. [Internet]. 2012 [acesso em: 07 nov. 2018];25(2):311-6. Disponível em: https://doi.org/10.1590/S0103-51502012000200008.

2. Shin YK, Yoon YK, Chung KB, Rhee Y, Cho SR. Patients with non-ambulatory cerebral palsy have higher sclerostin levels and lower bone mineral density than patients with ambulatory cerebral palsy. Bone [Internet]. 2017 [acesso em: 07 nov.

2018];103:302-7. Disponível em: https://doi.org/10.1016/j.bone.2017.07.015.

3. Khouri N, Desailly E. Contribution of clinical gait analysis to single-event multi-level surgery in children with cerebral palsy. Orthop Traumatol Surg Res [Internet]. 2017 [acesso em: 07 nov. 2018];103(1 Supl):S105-11. Disponível em:

https://doi.org/10.1016/i.otsr.2016.11.004.

4. Lee KM, Kang JY, Chung CY, Kwon DG, Lee SH, Choi IH, et al. Clinical relevance of valgus deformity of proximal femur in cerebral palsy. J Pediatr Orthop [Internet]. 2010 [acesso em: 07 nov. 2018];30(7):720-5. Disponível em: https://doi.org/10.1097/BPO.0b013e3181edba2a.

5. Trabacca A, Vespino T, Di Liddo A, Russo L. Multidisciplinary rehabilitation for patients with cerebral palsy: improving longterm care. J Multidiscip Healthc [Internet]. 2016 [acesso em: 07 nov. 2018];9:455-62. Disponível em:

https://doi.org/10.2147/JMDH.S88782.

6. Chen YP, Lee SY, Howard AM. Effect of virtual reality on upper extremity function in children with cerebral palsy: a metaanalysis. Pediatr Phys Ther [Internet]. 2014 [acesso em: 07 nov. 2018];26(3):289-300. Disponível em: https://doi.org/10.1097/PEP.0000000000000046.

7. Sandlund M, Waterworth EL, Häger C. Using motion interactive games to promote physical activity and enhance motor performance in children with cerebral palsy. Dev Neurorehabil [Internet]. 2011 [acesso em: 07 nov. 2018];14(1):15-21. Disponível em: https://doi.org/10.3109/17518423.2010.533329.

8. Bonnechère $B$, Jansen $B$, Omelina L, Degelaen $M$, Wermenbol V, Rooze $M$, et al. Can serious games be incorporated with conventional treatment of children with cerebral palsy? A review. Res Dev Disabil [Internet]. 2014 [acesso em: 07 nov. 2018];35(8):1899-913. Disponível em: https://doi.org/10.1016/j.ridd.2014.04.016.

9. Oliveira LB, Dantas ACLMD, Paiva JC, Leite LP, Ferreira PHL, Abreu TMA. Recursos fisioterapêuticos na paralisia cerebral pediátrica. Catussaba [Internet]. 2013 [acesso em: 07 nov. 2018];2(2):25-37. Disponível em:

https://repositorio.unp.br/index.php/catussaba/article/view/296.

10. Caricchio MBM. Tratar brincando: o lúdico como recurso da fisioterapia pediátrica no Brasil. Revista Atualiza Saúde [Internet]. 2017 [acesso em: 07 nov. 2018];6(6):43-57. Disponível em: http://atualizarevista.com.br/wp-

content/uploads/2017/08/tratar-brincando-o-lúdico-como-recurso-da-fisioterapia-pediátrica-no-brasil-v-6-n-6.pdf.

11. Byrne R, Noritz G, Maitre NL. Implementation of Early Diagnosis and Intervention Guidelines for Cerebral Palsy in a HighRisk Infant Follow-Up Clinic. Pediatr Neurol [Internet]. 2017 [acesso em: 07 nov. 2018];76:66-71. Disponível em:

https://doi.org/10.1016/j.pediatrneurol.2017.08.002.

12. Soares CB, Hoga LA, Peduzzi M, Sangaleti C, Yonekura T, Silva DR. Integrative review: concepts and methods used in nursing. Rev Esc Enferm USP [Internet]. 2014 [acesso em: 07 nov. 2018];48(2):335-45. Disponível em:

https://doi.org/10.1590/S0080-6234201400002000020.

13. Liberati A, Altman DG, Tetzlaff J, Mulrow C, Gøtzsche PC, loannidis JPA, et al. The PRISMA Statement for Reporting Systematic Reviews and Meta-Analyses of Studies That Evaluate Health Care Interventions: Explanation and Elaboration. PLoS Med [Internet]. 2009 [acesso em: 07 nov. 2018];6(7):e1000100. Disponível em:

https://doi.org/10.1371/journal.pmed.1000100.

14. Viera AJ, Garrett JM. Understanding interobserver agreement: the kappa statistic. Fam Med [Internet]. 2005 [acesso em: 07 nov. 2018];37(5):360-3. Disponível em: http://www.stfm.org/fmhub/fm2005/May/Anthony360.pdf.

15. Moher D, Liberati A, Tetzlaff J, Altman DG. Preferred reporting items for systematic reviews and meta-analyses: the PRISMA statement. Int J Surg [Internet]. 2010 [acesso em: 07 nov. 2018];8(5):336-41. Disponível em:

https://doi.org/10.1016/j.ijsu.2010.02.007.

16. Chen YP, Kang LJ, Chuang TY, Doong JL, Lee SJ, Tsai MW, et al. Use of virtual reality to improve upper-extremity control in children with cerebral palsy: a single-subject design. Phys Ther [Internet]. 2007 [acesso em: 07 nov. 2018];87(11):1441-57. Disponível em: https://doi.org/10.2522/ptj.20060062.

17. Fasoli SE, Fragala-Pinkham M, Hughes R, Hogan N, Krebs HI, Stein J. Upper limb robotic therapy for children with hemiplegia. Am J Phys Med Rehabil [Internet]. 2008 [acesso em: 07 nov. 2018];87(11):929-36. Disponível em: https://doi.org/10.1097/PHM.0b013e31818a6aa4. 
18. Crajé C, Aarts $P$, Nijhuis-van der Sanden M, Steenbergen B. Action planning in typically and atypically developing children (unilateral cerebral palsy). Res Dev Disabil [Internet]. 2010 [acesso em: 07 nov. 2018];31(5):1039-46. Disponível em:

https://doi.org/10.1016/j.ridd.2010.04.007.

19. Aarts PB, van Hartingsveldt M, Anderson PG, van den Tillaar I, van der Burg J, Geurts AC. The Pirate group intervention protocol: description and a case report of a modified constraint-induced movement therapy combined with bimanual training for young children with unilateral spastic cerebral palsy. Occup Ther Int [Internet]. 2012 [acesso em: 07 nov. 2018];19(2):76-87. Disponível em: https://doi.org/10.1002/oti.321.

20. Frank A, McCloskey S, Dole RL. Effect of hippotherapy on perceived self-competence and participation in a child with cerebral palsy. Pediatr Phys Ther [Internet]. 2011 [acesso em: 07 nov. 2018];23(3):301-8. Disponível em:

https://doi.org/10.1097/PEP.0b013e318227caac.

21. Gordon C, Roopchand-Martin S, Gregg A. Potential of the Nintendo $\mathrm{Wii}^{\mathrm{TM}}$ as a rehabilitation tool for children with cerebral palsy in a developing country: a pilot study. Physiotherapy [Internet]. 2012 [acesso em: 07 nov. 2018];98(3):238-42. Disponível em: https://doi.org/10.1016/i.physio.2012.05.011.

22.Sharan D, Ajeesh PS, Rameshkumar R, Mathankumar M, Paulina RJ, Manjula M. Virtual reality based therapy for post operative rehabilitation of children with cerebral palsy. Work [Internet]. 2012 [acesso em: 07 nov. 2018];41 Suppl 1:3612-5. Disponível em: https://doi.org/10.3233/WOR-2012-0667-3612.

23. Barton GJ, Hawken MB, Foster RJ, Holmes G, Butler PB. The effects of virtual reality game training on trunk to pelvis coupling in a child with cerebral palsy. J Neuroeng Rehabil [Internet]. 2013 [acesso em: 07 nov. 2018];10:15. Disponível em: https://doi.org/10.1186/1743-0003-10-15.

24. Burdea GC, Cioi D, Kale A, Janes WE, Ross SA, Engsberg JR. Robotics and gaming to improve ankle strength, motor control, and function in children with cerebral palsy--a case study series. IEEE Trans Neural Syst Rehabil Eng [Internet]. 2013 [acesso em: 07 nov. 2018];21(2):165-73. Disponível em: https://doi.org/10.1109/TNSRE.2012.2206055.

25. Luna-Oliva L, Ortiz-Gutiérrez RM, Cano-de la Cuerda R, Piédrola RM, Alguacil-Diego IM, Sánchez-Camarero C, et al. Kinect Xbox 360 as a therapeutic modality for children with cerebral palsy in a school environment: A preliminary study. NeuroRehabilitation [Internet]. 2013 [acesso em: 07 nov. 2018];33(4):513-21. Disponível em: https://doi.org/10.3233/NRE131001.

26. Peper CLE, Van Loon ECP, Van de Rijt A, Salverda A, Van Kuijk AA. Bimanual training for children with cerebral palsy: Exploring the effects of Lissajous-based computer gaming. Dev Neurorehabil [Internet]. 2013 [acesso em: 07 nov. 2018];16(4):255-65. Disponível em: https://doi.org/10.3109/17518423.2012.760116.

27. Curtis DJ, Bencke J, Mygind B. The effect of training in an interactive dynamic stander on ankle dorsiflexion and gross motor function in children with cerebral palsy. Dev Neurorehabil [Internet]. 2014 [acesso em: 07 nov. 2018];17(6):393-7. Disponível em: https://doi.org/10.3109/17518423.2013.844738.

28. Huang HH, Ragonesi CB, Stoner T, Peffley T, Galloway JC. Modified Toy Cars for Mobility and Socialization. Pediatr Phys Ther [Internet]. 2014 [acesso em: 07 nov. 2018];26(1):76-84. Disponível em:

https://doi.org/10.1097/PEP.0000000000000001.

29. Ni LT, Fehlings D, Biddiss E. Design and Evaluation of Virtual Reality-Based Therapy Games with Dual Focus on Therapeutic Relevance and User Experience for Children with Cerebral Palsy. Games Health J [Internet]. 2014 [acesso em: 07 nov. 2018];3(3):162-71. Disponível em: https://doi.org/10.1089/g4h.2014.0003.

30. Preston N, Weightman A, Gallagher J, Holt R, Clarke M, Mon-Williams M, et al. Feasibility of school-based computerassisted robotic gaming technology for upper limb rehabilitation of children with cerebral palsy. Disabil Rehabil Assist Technol [Internet]. 2016 [acesso em: 07 nov. 2018];11(4):281-8. Disponível em:

https://doi.org/10.3109/17483107.2014.932020.

31. AlSaif AA, Alsenany S. Effects of interactive games on motor performance in children with spastic cerebral palsy. J Phys Ther Sci [Internet]. 2015 [acesso em: 07 nov. 2018];27(6):2001-3. Disponível em: https://doi.org/10.1589/jpts.27.2001. 32. Tong LZ, Ong HT, Tan JX, Lin J, Burdet E, Ge SS, et al. Pediatric rehabilitation with the reachMAN's modular handle. In: 2015 37th Annual International Conference of the IEEE Engineering in Medicine and Biology Society (EMBC) [Internet]. IEEE; 2015 [acesso em: 07 nov. 2018]. p. 3933-6. Disponível em: https://doi.org/10.1109/EMBC.2015.7319254.

33. Pratt B, Hartshorne NS, Mullens P, Schilling ML, Fuller S, Pisani E. Effect of Playground Environments on the Physical Activity of Children With Ambulatory Cerebral Palsy. Pediatr Phys Ther [Internet]. 2016 [acesso em: 07 nov. 2018];28(4):47582. Disponível em: https://doi.org/10.1097/PEP.0000000000000318.

34. Do JH, Yoo EY, Jung MY, Park HY. The effects of virtual reality-based bilateral arm training on hemiplegic children's upper limb motor skills. NeuroRehabilitation [Internet]. 2016 [acesso em: 07 nov. 2018];38(2):115-27. Disponível em:

https://doi.org/10.3233/NRE-161302. 
35. Senapati B. The Effectiveness of Play Activities and Functional Activities on Fine Motor Skills in Children with Spastic Diplegic Cerebral Palsy. Indian J Physiother Occup Ther - An Int J [Internet]. 2017 [acesso em: 07 nov. 2018];11(1):85. Disponível em: https://doi.org/10.5958/0973-5674.2017.00017.X.

36. Pavão SL, Arnoni JLB, Oliveira AKC de, Rocha NACF. Impact of a virtual reality-based intervention on motor performance and balance of a child with cerebral palsy: a case study. Rev Paul Pediatr [Internet]. 2014 [acesso em: 07 nov.

2018];32(4):389-94. Disponível em: https://doi.org/10.1016/j.rpped.2014.04.005.

37. Silva PC, Santos A, Oliveira E, Ventura G, Gonzaga I, Araújo V. Efeitos da intervenção de jogos X-BOX 360, nas habilidades sensório-motoras de uma criança com paralisia cerebral: estudo de caso. Diálogos \& Ciência [Internet]. 2016 [acesso em: 07 nov. 2018];(36):73-87. Disponível em: http://periodicos.ftc.br/index.php/dialogos/article/view/17.

38. Kleiner AFR, Schlittler DXC, Sánchez-Arias MR. O papel dos sistemas visual, vestibular, somatosensorial e auditivo para o controle postural. Revista Neurociências [Internet]. 2011 [acesso em: 07 nov. 2018];19(2):349-57. Disponível em:

http://www.revistaneurociencias.com.br/edicoes/2011/RN1902/revisao\%2019\%2002/496\%20revisao.pdf.

39. Fonseca LJP, Brandalize M, Brandalize D. Nintendo WII na reabilitação de pacientes com paralisia cerebral - relato de caso. Arquivos de Ciências da Saúde da UNIPAR [Internet]. 2012 [acesso em: 07 nov. 2018];16(1):39-43. Disponível em: http://revistas.unipar.br/index.php/saude/article/view/4565.

40. Maitre NL, Chorna O, Romeo DM, Guzzetta A. Implementation of the Hammersmith Infant Neurological Examination in a High-Risk Infant Follow-Up Program. Pediatr Neurol [Internet]. 2016 [acesso em: 07 nov. 2018];65:31-8. Disponível em: https://doi.org/10.1016/j.pediatrneurol.2016.09.010.

41. Castro DF, Tredezini ALM. A importância do jogo/lúdico no processo de ensino-aprendizagem. Perquirere [Internet]. 2014 [acesso em: 07 nov. 2018];11(1):166-81. Disponível em:

http://perquirere.unipam.edu.br/documents/23456/422843/A+++importância+do+jogo-lúdico+no+processo+de+ensinoaprendizagem.pdf.

42. Rézio GS, Cunha JOV, Formiga CKMR. Estudo da independência funcional, motricidade e inserção escolar de crianças com Paralisia Cerebral. Rev. bras. educ. espec. [Internet]. 2012 [acesso em: 07 nov. 2018];18(4):601-14. Disponível em: https://doi.org/10.1590/S1413-65382012000400005.

43. Ríos-Rincón AM, Adams K, Magill-Evans J, Cook A. Playfulness in Children with Limited Motor Abilities When Using a Robot. Phys Occup Ther Pediatr [Internet]. 2016 [acesso em: 07 nov. 2018];36(3):232-46. Disponível em:

https://doi.org/10.3109/01942638.2015.1076559.

44. Moraes A, Silva M, Copetti F, Abreu AC, David AC. Equoterapia no controle postural e equilíbrio em indivíduos com paralisia cerebral: revisão sistemática. Revista Neurociências [Internet]. 2015 [acesso em: 07 nov. 2018];23(4):546-54. Disponível em: https://doi.org/10.4181/RNC.2015.23.04.1062.09p.

45. Cobanoglu M, Cullu E, Omurlu I. The effect of hip reconstruction on gross motor function levels in children with cerebral palsy. Acta Orthop Traumatol Turc [Internet]. 2018 [acesso em: 07 nov. 2018];52(1):44-8. Disponível em:

https://doi.org/10.1016/j.aott.2017.11.001.

46. Silva NDSH, Lamy Filho F, Gama MEA, Lamy ZDC, Pinheiro ADL, Silva DDN. Instrumentos de avaliação do desenvolvimento infantil de recém-nascidos prematuros. J Hum Growth Dev [Internet]. 2011 [acesso em: 07 nov. 2018];21(1):85-98. Disponível em: https://doi.org/10.7322/jhgd.19998.

47. Pérez-de la Cruz S. Cerebral palsy and the use of positioning systems to control body posture: current practices. Neurología (English Edition) [Internet]. 2017 [acesso em: 07 nov. 2018];32(9):610-5. Disponível em:

https://doi.org/10.1016/j.nrleng.2015.05.015.

48. Krebs RJ, Carniel JD, Machado Z. Contexto de desenvolvimento e a percepção espacial de crianças. Movimento [Internet]. 2011 [acesso em: 07 nov. 2018];17(1):195-211. Disponível em:

https://seer.ufrgs.br/Movimento/article/view/15483.

49. Wright A, Roberts R, Bowman G, Crettenden A. Barriers and facilitators to physical activity participation for children with physical disability: comparing and contrasting the views of children, young people, and their clinicians. Disabil Rehabil [Internet]. 2018 [acesso em: 07 nov. 2018]:1-9. Disponível em: https://doi.org/10.1080/09638288.2018.1432702. 